\title{
New approaches to managing asthma: a US perspective
}

\section{William E Berger}

Allergy and Asthma Associates of Southern California, Mission Viejo, CA, USA
Correspondence: William E Berger Allergy and Asthma Associates of Southern California, 27800 Medical Center Road, Suite 244, Mission Viejo, CA $92691-6410$, USA

Tel + I 9493642900

$\mathrm{Fax}+19493650117$

Email weberger@uci.edu

\begin{abstract}
Despite remarkable advances in diagnosis and long-term management, asthma remains a serious public health concern. Newly updated expert guidelines emphasize the intraand inter-individual variability of asthma and highlight the importance of periodic assessment of asthma control. These guidelines update recommendations for step-wise asthma treatment, address the burgeoning field of asthma diagnostics, and stress the importance of a patient and health care professional partnership, including written action plans and self monitoring. The field of asthma therapeutics is expanding rapidly, with promising new treatment options available or in development that may address some of the existing barriers to successful asthma management. These approaches simplify treatment, use combinations of agents in one delivery device that have complementary actions, or target specific pathways involved in asthma pathophysiology. Considerable activity is taking place in asthma pharmacogenetics. This review provides an overview of these new approaches to managing asthma, including their present status and future potential.
\end{abstract}

Keywords: asthma treatment, inhaled corticosteroids, long-acting $\beta_{2}$-adrenergic agonists, guidelines, pharmacogenetics

\section{Introduction}

The modern age of asthma treatment began more than 50 years ago with the introduction of the first pressurized metered-dose inhaler (pMDI) in 1956 (Crompton 2006). The pMDI provided convenient delivery of effective bronchodilator therapy. Patients with asthma used the rapidly acting nonselective $\beta$-agonists (ie, isoprenaline and epinephrine) through the mid 1960s, when the number of asthma-related deaths skyrocketed (Crompton 2006). The increased death rate was attributed to a decreased response to nonselective $\beta$-agonists that prompted patients to overuse their inhalers. Reduced sensitivity to bronchodilators became recognized as a harbinger of severe, lifethreatening asthma attacks. Subsequent warnings from regulatory agencies markedly reduced the use of the nonselective $\beta$-agonists. The selective short-acting $\beta_{2}$-adrenergic agonist (SABA) salbutamol, called albuterol in the US, replaced the nonselective agents (Crompton 2006) and has been demonstrated to be a safe and effective bronchodilator (Drazen et al 1996; Dennis et al 2000; NAEPP 2007). During this time, the goal of asthma treatment shifted from managing bronchospasm to preventing inflammation.

Systemic corticosteroids, long recognized as an effective anti-inflammatory treatment for asthma, were associated with serious systemic adverse events when used long term (Crompton 2006). Delivery of inhaled corticosteroids (ICSs) via a pMDI in the early 1970s ushered in a new era of asthma management (Crompton 2006). By the late 1980s and 1990s, the efficacy of anti-inflammatory therapy using ICSs was realized, and ICSs became established as first-line therapy for patients with asthma. However, clinical response to ICS therapy can vary among patients with asthma, and the dose-response curve for ICS treatment plateaus for many efficacy 
measures at low to medium doses (NAEPP 2007); thus, a need for new therapies became evident. A novel class of asthma therapies was introduced in the 1990s that targeted the synthesis or activity of the leukotriene family of inflammatory mediators in the pathogenesis of asthma (Holgate et al 1996). Leukotriene modifiers (LTMs) generally have been shown to be less effective than ICSs (Ducharme and Di Salvio 2004), possibly because they target only the leukotriene pathway of inflammation, whereas ICSs have a broader anti-inflammatory effect.

Although the selective long-acting $\beta_{2}$-adrenergic agonist (LABA) salmeterol was introduced as monotherapy in the late 1980s and early 1990s, concerns about the risk of severe asthma attacks associated with SABAs carried over to this class of therapy (Crompton 2006). Moreover, studies demonstrated that monotherapy with a LABA was insufficient to control asthma (Lazarus et al 2001; Lemanske et al 2001). Concerns regarding the safety of high-dose ICSs (eg, rare cases of adrenal suppression) and findings from randomized, controlled trials showing a more effective reduction in symptoms and exacerbations with a reduced ICS dose and a LABA (eg, salmeterol or formoterol) compared with high-dose ICS alone eventually cemented the role of LABA in the therapeutic armamentarium (Greening et al 1994; Pauwels et al 1997; Crompton 2006). Indeed, contemporary asthma treatment guidelines recommend add-on LABA to ICS therapy for those patients who do not respond optimally to low- to medium-dose ICS (Crompton 2006; GINA 2007; NAEPP 2007).

Despite these advances in therapy, which have contributed to declines in asthma morbidity and mortality in the US, asthma continues to pose a significant personal and economic burden (ALA 2006; GINA 2007; NAEPP 2007). Barriers to improving the burden of asthma are patient variability and poor patient adherence to therapy. In any given patient, the frequency and severity of symptoms, pulmonary function, airway hyper-responsiveness, inflammation, and exacerbations vary over time (GINA 2007; NAEPP 2007). Moreover, tremendous inter-patient variability in the natural course and treatment response of asthma is attributed to the interaction of genetic predisposition, individual patient characteristics (eg, obesity, sex, pregnancy), and exposure to environmental insults (eg, air pollution, allergens, cigarette smoke) (GINA 2007; NAEPP 2007). Asthma is a complex disorder with multiple phenotypes and genotypes, which contribute to heterogeneity in response to therapy (Szefler et al 2005; Wechsler and Israel 2005; Hines and McCarver 2006; GINA 2007; NAEPP 2007). For example, children with an allergic phenotype responded better to ICS therapy than to LTM therapy (Szefler et al 2005). Additionally, it has been postulated that differential patient response to therapy with LABAs and SABAs is associated with polymorphisms in the $\beta_{2}$-adrenergic receptor gene; however, results from small studies are conflicting (Hancox et al 1998; Israel et al 2000; Taylor et al 2000; Dorinsky et al 2004; Israel et al 2004; Bleecker et al 2006; Wechsler et al 2006; Goldman et al 2007). However, two recent large studies demonstrated that genotype $(\mathrm{n}=2630)$ did not affect treatment response to LABA when administered with ICS (Bleecker et al 2007). Although lack of response to ICS therapy also has been associated with a specific phenotype and genotype (GINA 2007), poor adherence can be a cause of therapeutic failure. Studies show that overall adherence to ICS therapy is about $50 \%$ (Williams et al 2004; Walders et al 2005). Complex or frequent dosing regimens are associated with poor adherence (Claxton 2001; GINA 2007); still, current therapies for asthma often require multiple medications delivered more than once daily (GINA 2007; NAEPP 2007). Furthermore, asthma may be variable in an individual patient; therefore, flexible treatment strategies that enable a step up or step down in treatment to achieve asthma control based on changes in symptoms and other facets of the disease are needed (Kips 2002). In summary, no single treatment approach is appropriate for all patients.

Asthma therapeutics is a rapidly evolving field. Updated expert guidelines on the prevention, diagnosis, and management of asthma are now available. This paper reviews the new guidelines and introduces emerging diagnostic, treatment, and monitoring options for asthma.

\section{Recommendations from current asthma guidelines}

Two recently revised expert guidelines review available data and place into perspective the many advances in the pharmacologic treatment of asthma achieved over the past decades. In the US, the National Asthma Education and Prevention Program (NAEPP) of the National Heart, Lung, and Blood Institute publishes and periodically updates diagnosis and management guidelines aimed at translating basic science and clinical research findings into clinical practice and improving patient outcomes. The third edition of the NAEPP guidelines was recently released (NAEPP 2007). The most current revision to the guidelines from the Global Initiative for Asthma (GINA) reviews recent data and outlines currently accepted strategies for managing asthma from a global perspective (GINA 2007). 
In the new updates, the NAEPP and GINA guidelines now recognize that asthma management is governed by three domains: disease severity, control, and response to treatment (GINA 2007; NAEPP 2007). Categorization of patients as having intermittent, mild persistent, moderate persistent, or severe persistent asthma is useful during initial clinical assessments to establish an initial treatment regimen. However, the severity of symptoms, lung function assessments, exacerbations, and need for SABA typically vary over time. Further, measures of disease severity are relatively insensitive predictors of treatment response. Thus, assessment of asthma control, rather than disease severity, is now considered the preferred approach for routine clinical monitoring and guiding decisions about maintaining or altering treatment (Table 1) (NAEPP 2007). Asthma control should be assessed at 1- to 6-month intervals by the health care professional (NAEPP 2007).

Table I Assessing asthma control in patients aged $\geq 12$ years (NAEPP 2007)

\begin{tabular}{|c|c|c|c|c|}
\hline \multirow[t]{2}{*}{ Components of control } & & \multicolumn{3}{|c|}{ Classification of asthma control ( $\geq 12$ years of age)* } \\
\hline & & Well controlled & Not well controlled & Very poorly controlled \\
\hline \multirow[t]{9}{*}{ Impairment } & Symptoms & $\leq 2$ days/week & $>2$ days/week & Throughout the day \\
\hline & Nighttime awakenings & $\leq 2 \times /$ month & $\mathrm{I}-3 \times /$ week & $\geq 4 \times /$ week \\
\hline & $\begin{array}{l}\text { Interference with normal } \\
\text { activity }\end{array}$ & None & Some limitation & Extremely limited \\
\hline & $\begin{array}{l}\text { Short-acting } \beta_{2} \text {-adrenergic } \\
\text { agonist use for symptom } \\
\text { control (not prevention } \\
\text { of EIB) }\end{array}$ & $\leq 2$ days/week & $>2$ days/week & Several times per day \\
\hline & FEV, or peak flow & $\begin{array}{l}>80 \% \text { predicted/ } \\
\text { personal best }\end{array}$ & $\begin{array}{l}60 \%-80 \% \text { predicted/ } \\
\text { personal best }\end{array}$ & $\begin{array}{l}<60 \% \text { predicted/ } \\
\text { personal best }\end{array}$ \\
\hline & Validated questionnaires ${ }^{\dagger}$ & & & \\
\hline & ATAQ & 0 & $\mathrm{I}-2$ & $3-4$ \\
\hline & $\mathrm{ACQ}$ & $\leq 0.75$ & $\geq 1.5$ & $\mathrm{~N} / \mathrm{A}$ \\
\hline & $\mathrm{ACT}$ & $\geq 20$ & $16-19$ & $\leq 15$ \\
\hline \multirow[t]{3}{*}{ Risk } & $\begin{array}{l}\text { Exacerbations } \\
\text { requiring oral systemic } \\
\text { corticosteroids }^{\ddagger}\end{array}$ & $\begin{array}{l}0-I \text { per year } \\
\text { Consider severity and interv }\end{array}$ & $\geq 2$ per year & \\
\hline & $\begin{array}{l}\text { Progressive loss of lung } \\
\text { function }\end{array}$ & Evaluation requires long-terr & follow-up care & \\
\hline & $\begin{array}{l}\text { Treatment-related adverse } \\
\text { effects }\end{array}$ & \multicolumn{3}{|c|}{$\begin{array}{l}\text { Medication side effects can vary in intensity from none to very troublesome/worrisome. } \\
\text { The level of intensity does not correlate to specific levels of control, but should be } \\
\text { considered in the overall assessment of risk. }\end{array}$} \\
\hline $\begin{array}{l}\text { Recommended } \\
\text { action for treatment } \\
\text { (see Figure I) }\end{array}$ & & $\begin{array}{l}\text { - Maintain current step } \\
\text { - Regular follow-ups every } \\
\text {-6 months to maintain } \\
\text { control } \\
\text { - Consider step-down if } \\
\text { well controlled for at } \\
\text { least } 3 \text { months }\end{array}$ & 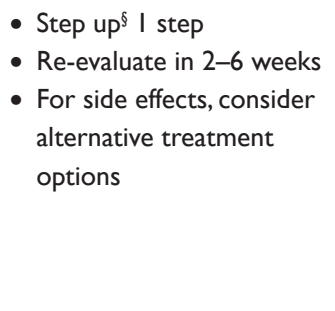 & $\begin{array}{l}\text { - Consider short course } \\
\text { of systemic oral } \\
\text { corticosteroids } \\
\text { - Step up } \text { I-2 steps }^{\text {- Re-evaluate in } 2 \text { weeks }} \\
\text { - For side effects, consider } \\
\text { alternative treatment } \\
\text { options }\end{array}$ \\
\hline
\end{tabular}

*The stepwise approach is meant to assist, not replace, the clinical decision making required to meet individual patient needs. The level of control is based on the most severe impairment or risk category. Assess impairment domain by patient's recall of previous 2-4 weeks and by spirometry/or peak flow measures. Symptom assessment for longer periods should reflect a global assessment, such as inquiring whether the patient's asthma is better or worse since the last visit.

†Validated questionnaires for the impairment domain (the questionnaires do not access assess lung function or the risk domain). Minimal important difference: I.0 for the ATAQ; 0.5 for the ACQ; not determined for the ACT. ACQ values 0.76-1.4 are indeterminate regarding well-controlled asthma.

${ }^{\ddagger}$ At present, there are inadequate data to correspond frequencies of exacerbations with different levels of asthma control. In general, more frequent and intense exacerbations (eg, requiring urgent, unscheduled care, hospitalization, or ICU admission) indicate poorer disease control. For treatment purposes, patients who had $\geq 2$ exacerbations requiring oral systemic corticosteroids in the past year may be considered the same as patients who have not-well-controlled asthma, even in the absence of impairment levels consistent with not-well-controlled asthma.

${ }^{\S}$ Before step-up in therapy, review adherence, environmental control, and comorbid conditions. If an alternative treatment option was used in a step, discontinue and use the preferred treatment for the step.

Abbreviations: EIB, exercise-induced bronchospasm; FEV , forced expiratory volume in I second; ATAQ, Asthma Therapy Assessment Questionnaire ${ }^{\odot}$; ACQ, Asthma Control Questionnaire $^{\odot} ; \mathrm{ACT}$, Asthma Control Test ${ }^{\mathrm{TM}}$; ICU, intensive care unit; N/A, not available. 
No cure exists for asthma; however, the use of optimally effective treatment regimens can achieve control (GINA 2007). Asthma control embodies the dual concepts of minimizing impairment and reducing risk for deterioration and exacerbations (NAEPP 2007). This new emphasis on regular assessment of asthma control is a key paradigm shift in the updated NAEPP and GINA guidelines. Both sets of guidelines focus on the importance of forming a patient - clinician alliance to foster long-term treatment adherence and achieve optimal asthma control. These guidelines also advocate patient education, the use of guided self-management, and the individualization of treatment plans (GINA 2007; NAEPP 2007). The educational process begins at diagnosis and continues throughout follow-up care, with the patient (or caregiver in the case of children) and health care provider working together to develop goals and a personalized, written self-management plan. These plans include guidelines for patient-guided adjustment of medications when needed for deteriorating asthma control or exacerbations.
The NAEPP and GINA guidelines discuss the place of available pharmacologic treatments in asthma therapy, categorizing them as drugs used for long-term control or immediate relief of acute symptoms and exacerbations (GINA 2007; NAEPP 2007). In all age groups and asthma severity levels, SABAs (NAEPP or GINA) and the LABA formoterol (GINA only) are considered the agents of choice for rapid relief of bronchoconstriction or for prevention of exercise-induced asthma. In Europe, formoterol is the only LABA indicated for rapid relief of bronchoconstriction; it is to be used as a reliever only in patients being treated with an ICS. The need for higher or more frequent SABA or LABA doses suggests deteriorating asthma control and is an indication for medical attention and increased therapy. Stepwise pharmacologic management algorithms for controller therapy are available in both guidelines; the NAEPP has a new 6-step approach, while GINA has revised their 5-step approach. The NAEPP algorithm for adults and adolescents aged 12 years or older is shown in Figure 1.

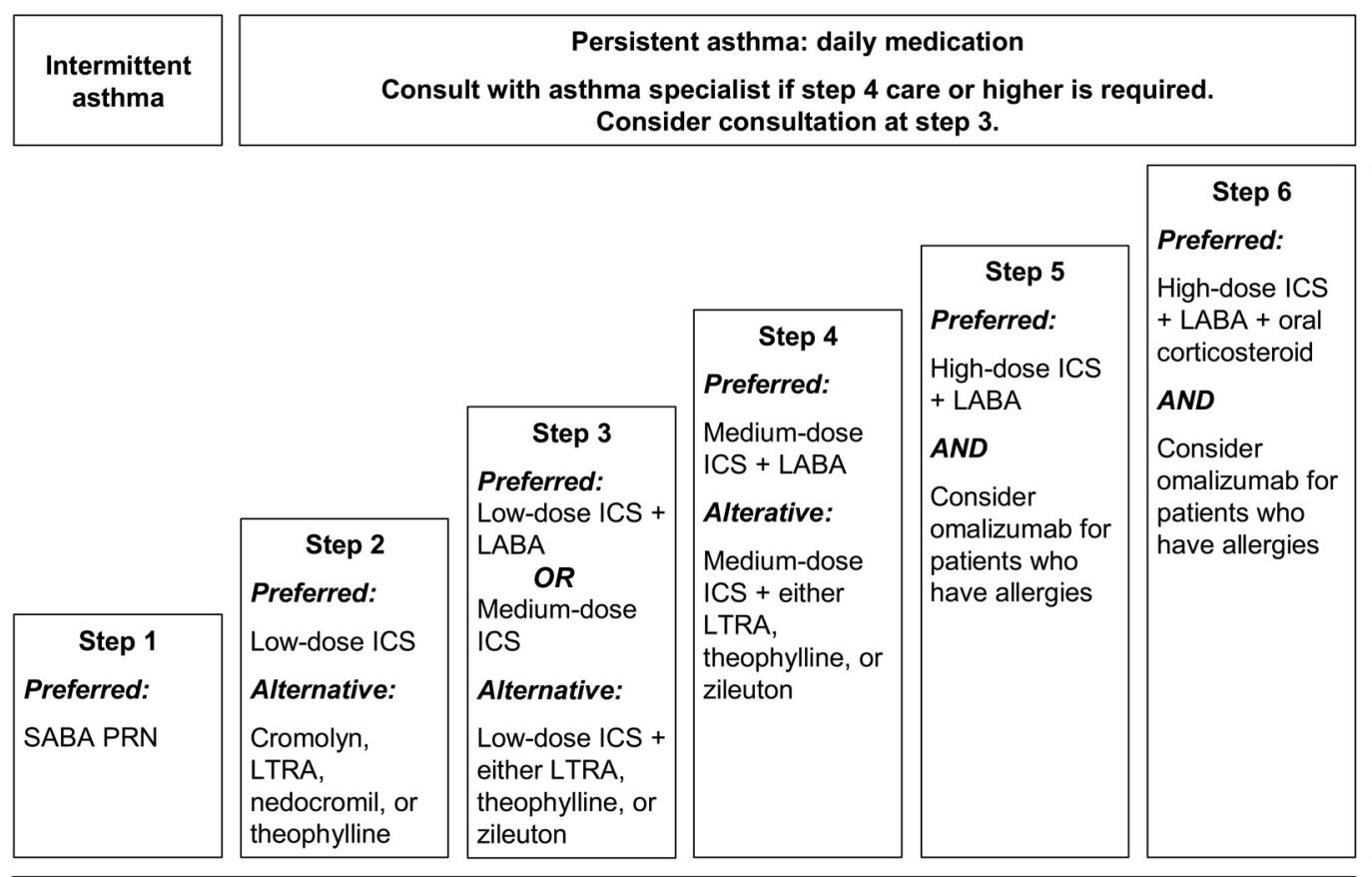

Each step: patient education, environmental control, and management of comorbidities.

Steps 2-4: consider subcutaneous allergen immunotherapy for patients who have allergic asthma.

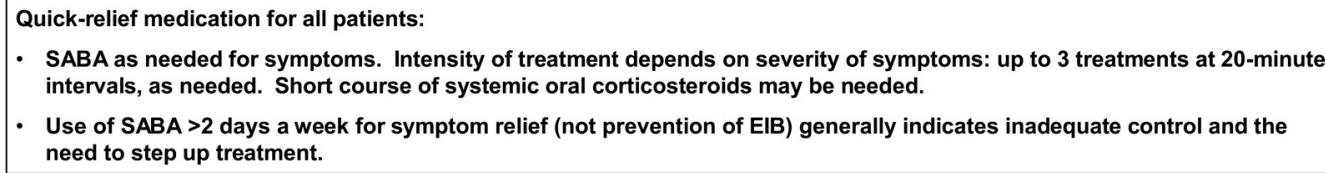

- SABA as needed for symptoms. Intensity of treatment depends on severity of symptoms: up to 3 treatments at 20-minute intervals, as needed. Short course of systemic oral corticosteroids may be needed.

- Use of SABA >2 days a week for symptom relief (not prevention of EIB) generally indicates inadequate control and the need to step up treatment.

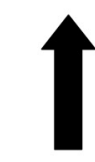

Step up if
needed
(first, check
adherence,
environmental
control, and
comorbid
conditions)
Assess
control

Step down if
possible
(and asthma is
well controlled
at least 3
months)

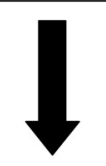

Figure I Asthma management approach based on control for adults and adolescents 12 years of age and older.

Abbreviations: EIB, exercise-induced bronchospasm; ICS, inhaled corticosteroid; LABA, long-acting $\beta_{2}$-agonist; LTRA, leukotriene receptor antagonist; PRN, pro re nata (as needed); SABA, short-acting $\beta_{2}$-adrenergic agonist. 
In both sets of guidelines, low-dose ICSs remain first-line therapy for control of persistent asthma in adults and older children (Figure 1) because of their potent anti-inflammatory effects and effectiveness compared with other therapies (GINA 2007; NAEPP 2007). Several ICSs are on the market, each with a unique bioavailability and potency profile. Although studies of equipotent doses are imperfect (Selroos 2007), the GINA and NAEPP guidelines provide estimated dose ranges for low-dose, medium-dose, and high-dose ICS therapy based on published comparative clinical trials and dose-ranging studies. For example, the NAEPP daily low-dose range is 180-600 $\mu \mathrm{g}$ for budesonide (BUD) DPI and 100-300 $\mu \mathrm{g}$ for fluticasone (FP) DPI (NAEPP 2007), whereas the GINA daily low-dose range is 200-400 $\mu \mathrm{g}$ for BUD and 100-250 $\mu \mathrm{g}$ for FP (GINA 2007). A low dose of an ICS is preferred step 2 therapy; however, monotherapy with a leukotriene receptor antagonist (LTRA) (montelukast, zafirlukast) or synthesis inhibitor (zileuton; GINA only) also is a recommended alternative treatment for patients aged 5 years or older. Montelukast also is recommended by the NAEPP for patients aged 0-4 years (GINA 2007; NAEPP 2007). Only the NAEPP guidelines recommend additional alternative choices for step 2 monotherapy - cromolyn (all ages), nedocromil ( $\geq 5$ years), and theophylline ( $\geq 5$ years). Monotherapy with a LABA is not recommended in either set of guidelines.

Guideline recommendations for patients who do not respond to low-dose ICS therapy (step 2) differ slightly between GINA and NAEPP (Figure 1) (GINA 2007; NAEPP 2007). In GINA, combination therapy with a lowdose ICS, and a LABA is the preferred next-step treatment for patients aged older than 5 years. In NAEPP, either this combination or a medium-dose ICS are preferred therapy for patients 12 years of age or older (step 3). For patients aged 5-11 years, the NAEPP gives equal preference to treatment with medium-dose ICS or low-dose ICS plus a LABA, LTRA, or theophylline (step 3). For patients whose asthma is not controlled on step 3 therapy, both sets of guidelines list medium- or high-dose ICS plus a LABA (steps 4 and 5 NAEPP, respectively; step 4 GINA) as preferred therapy. Notably, the fixed-dose combination ICS/LABA inhaler $\mathrm{BUD} /$ formoterol (FM) DPI is approved for use as maintenance and reliever therapy in Europe (Rabe et al 2006; Kuna et al 2007), but is approved only for maintenance use in the US. Combination therapy with a medium-dose ICS plus a LTRA, zileuton (NAEPP $\geq 12$ years; GINA $\geq 5$ years), or sustained-release theophylline are additional options for GINA and NAEPP step 4 therapy. The addition of oral corticosteroids to ICS plus LABA combination therapy is the preferred last step of GINA (step 5) and NAEPP (step 6) therapy. Anti-immunoglobulin E (IgE) treatment (omalizumab) also can be added for patients with allergies who do not respond to conventional therapy.

Finally, studies of asthma treatment in young children are limited; therefore, treatment recommendations are different for young children than for adults and older children (GINA 2007; NAEPP 2007). Evidence supports the use of ICS as the GINA- and NAEPP-preferred daily controller for infants and young children. The GINA and NAEPP recommend medium-dose ICS as the next-step treatment for children younger than 5 years whose asthma is not well controlled on low-dose ICS alone (GINA 2007; NAEPP 2007).

\section{New tools and parameters for asthma diagnosis and monitoring}

Routine, objective assessment of lung function is necessary to monitor asthma control and evaluate response to treatment. Spirometry, particularly a patient's forced expiratory volume in 1 second $\left(\mathrm{FEV}_{1}\right)$, and peak expiratory flow $(\mathrm{PEF})$ monitoring remain the cornerstones of noninvasive asthma assessment tools available to health care professionals (GINA 2007; NAEPP 2007). The GINA and NAEPP guidelines acknowledge the emerging research on these techniques. For instance, the NAEPP has added a recommendation to use the $\mathrm{FEV}_{1} /$ forced vital capacity ratio to classify asthma severity in children older than 4 years because of its sensitivity. Nonetheless, existing pulmonary function tests are effort dependent, requiring some degree of coordination on the part of the patient, and may be impractical for use in young children (GINA 2007).

Impulse oscillometry is a particularly useful measure of lung function in young children because it requires only passive cooperation (Marotta et al 2003). The patient breathes normally into a mouthpiece for a short period while a pulseshaped pressure flow excitation is delivered to the respiratory system by a loudspeaker. Resistance and reactance of the pulse by the child's respiratory system provides a measure of lung function. Impulse oscillometry has been shown to detect lung function abnormalities in young children at increased risk of persistent asthma, particularly those with atopic disease. In addition to new diagnostic and monitoring methods for lung function, development of new, accurate, and noninvasive tests to assess asthma control and exacerbation risk is proceeding at a rapid pace.

Measurement of biomarkers of lung inflammation is used in clinical research, and several techniques hold promise 
for future use in routine clinical practice. Nitric oxide (NO) is one mediator of inflammation. Clinically, the fractional concentration of exhaled NO (FeNO) distinguishes a patient with asthma not receiving anti-inflammatory treatment, correlates with other markers of disease severity and inflammation, and, in some studies, predicts responsiveness to corticosteroid therapy (ATS 2006; NAEPP 2007). An analyzer of FeNO is commercially available and has been approved for use in the US (NIOX ${ }^{\circledR}$ Flex, Aerocrine Inc., New York, USA) (Silkoff et al 2004; Alving et al 2006), but cost and reimbursement challenges have hindered widespread clinical use (ATS 2006). Another FeNO monitor that utilizes a biosensor platform and patented Sol-Gel technology is under development (Apieron Inc., Menlo Park, CA, USA). Eosinophils are important effector cells, and elevated levels in the sputum and peripheral blood are another well-recognized marker of inflammation in asthma. Measurement of sputum eosinophilia represents a possible tool for adjusting asthma therapy to reduce exacerbations in adult patients (Petsky et al 2007). However, standardization of methodology and the complexity of the measurement process currently limit the usefulness of this technique (NAEPP 2007). Finally, increased levels of $\mathrm{IgE}$ are present in patients with allergic airway inflammation. Children with elevated serum $\operatorname{IgE}$ levels have responded positively to ICS treatment, suggesting that this biomarker may be useful for guiding treatment decisions (Szefler et al 2005).

In summary, while the GINA and NAEPP guidelines recognize the potential usefulness of measuring FeNO, sputum eosinophils, and serum IgE, both fall short of recommending the widespread use of these and other biomarkers until further prospective, randomized, controlled studies in adults and children are conducted (GINA 2007; NAEPP 2007).

\section{Treatment update Monotherapy with an ICS}

ICSs are the first line of therapy for control of persistent asthma in adults and older children and considered the most effective anti-inflammatory treatment (GINA 2007; NAEPP 2007). A dry powder formulation of mometasone furoate (Asmanex ${ }^{\circledR}$ Twisthaler $220 \mu \mathrm{g}$, Schering Corporation, Kenilworth, NJ, USA) was approved in 2005 in the US for the maintenance treatment of asthma in patients 12 years of age or older (Asmanex ${ }^{\circledR}$ PI). In addition, a new dry powder formulation of BUD (Pulmicort Flexhaler ${ }^{\mathrm{TM}} 90 \mu \mathrm{g}, 180 \mu \mathrm{g}$; AstraZeneca, Wilmington, DE, USA) was recently approved in the US for maintenance treatment of asthma in adult and pediatric patients 6 years of age or older (Pulmicort Flexhaler PI). The new product has an indicator window that enables the patient to see approximately how many doses remain in the canister.

\section{Monotherapy or add-on therapy with a leukotriene modifier}

Leukotriene modifiers include two types of agents, the LTRAs, which are antagonists of cysteinyl leukotriene 1 (eg, montelukast [Singulair ${ }^{\circledR}$; Merck and Co., Inc., West Point, PA, USA], zafirlukast [Accolate ${ }^{\circledR}$; AstraZeneca LP; Wilmington, DE, USA]), and agents that block the synthesis of 5-lipoxygenase from arachidonic acid (zileuton [Zyflo ${ }^{\circledR}$; Critical Therapeutics Inc, Lexington, MA, USA]). Although a new formulation was launched in 2005 , zileuton has been available since 1997 as a 600-mg oral tablet that is administered four times daily in adults and children aged older than 12 years. A sustained-release formulation was approved for twice-daily administration in May 2007. Hepatic toxicity can occur during zileuton therapy (Wenzel 1998; Lazarus et al 1998). Therefore, pretreatment baseline and periodic monitoring of hepatic enzymes is recommended, particularly during treatment initiation (Wenzel 1998).

Sin et al conducted a systematic review and meta-analysis of therapies used in persistent asthma and concluded that the LTMs (including LTRAs and zileuton) were more effective than placebo in preventing asthma exacerbations, but less effective than ICS (Sin et al 2004). Indeed, the GINA guidelines consider zileuton to be an alternative, but not preferred, monotherapy for step 2 treatment; the NAEPP and GINA guidelines consider zileuton an alternative add-on therapy for step-up ( 3 or 4 ) care for adults and adolescents (Figure 1) (GINA 2007; NAEPP 2007). In patients with aspirin-intolerant asthma, addition of zileuton to usual ICS or oral corticosteroid therapy was associated with improvements in pulmonary function, and symptoms of rhinosinusitis and asthma (Dahlén et al 1998). A similarly designed study using montelukast was associated with similar benefits in patients with aspirinintolerant asthma (Dahlén et al 2002). Taken together, these studies show the important role of the leukotriene pathway in this disorder. In summary, zileuton may be an appropriate alternative treatment option as monotherapy for patients with mild persistent asthma, particularly those with a distinct asthma phenotype, and as an add-on therapy for patients with moderate or severe persistent asthma.

\section{ICS/LABA combination therapy}

The ICSs are considered the most effective anti-inflammatory treatment for control of persistent asthma, and inhaled $\beta_{2}$-adrenergic agonists are the most effective bronchodilators 
(Barnes 2002; NAEPP 2007). The ICSs inhibit eosinophils, macrophages, T-lymphocytes, mast cells, and other markers of inflammation. LABAs may possess anti-inflammatory properties or other beneficial pharmacologic effects that complement ICSs, such as inhibiting the release of inflammatory mediators from mast cells, blocking plasma exudates and reducing airway edema, and modulating airway sensory nerves that mediate airway hyper-responsiveness (Figure 2).

A Cochrane database systematic review of 30 randomized, controlled studies demonstrated that the addition of a LABA to ICS therapy was more effective than higher dose ICS monotherapy in preventing treatment discontinuations because of deteriorating asthma control in patients with primarily moderate disease (Greenstone et al 2005). An additional Cochrane review of 10 trials in adults with asthma maintained on moderate to high ICS doses demonstrated that LABA addition enabled an ICS dose reduction with improved or maintained asthma control (Gibson et al 2005). Combined therapy with low-dose ICS and LABA currently is used extensively for treatment of persistent asthma in the US and Europe.

Recognition of the efficacy and widespread use of combination therapy led to the development of fixed-dose combination inhalers (Barnes 2002; Miller-Larsson and Selroos 2006). Two ICS/LABA combinations currently are available as fixed-dose proprietary formulations. Fluticasone propionate and salmeterol (FP/SAL) is available as a DPI (Advair Diskus ${ }^{\circledR}$ 100/50 $\mu \mathrm{g}, 250 / 50 \mu \mathrm{g}, 500 / 50 \mu \mathrm{g}$; GlaxoSmithKline, Research Triangle Park, NC, USA; Seretide Diskus ${ }^{\circledR}$; GlaxoSmithKline, Middlesex, UK) and recently as a pMDI (Advair hydrofluoroalkane [HFA] 45/21 $\mu \mathrm{g}, 115 / 21 \mu \mathrm{g}, 230 / 21 \mu \mathrm{g}$; GlaxoSmithKline, Research Triangle Park, NC, USA). The FP/SAL HFA pMDI formulation demonstrated greater improvements in asthma control compared with the individual monocomponents (Pearlman et al 2004; Nathan et al 2006). The FP/SAL HFA pMDI at the initial formulation dosage of $50 / 25 \mu \mathrm{g} \times 2$ inhalations twice daily demonstrated similar efficacy and tolerability as FP/SAL DPI 100/50 $\mu \mathrm{g} \times 1$ inhalation once daily (Bateman et al 2001).

In 2000, BUD and FM in one inhaler (BUD/FM) became available outside of the US as a DPI (Symbicort Turbuhaler $^{\circledR}$; AstraZeneca, Lund, Sweden). In June 2007, a pMDI formulation of BUD/FM became available in the US (Symbicort inhalation aerosol 80/4.5 $\mu \mathrm{g}$ or 160/4.5 $\mu \mathrm{g}$; AstraZeneca LP, Wilmington, DE, USA). Therapeutic equivalence and similar tolerability has been demonstrated for BUD/FM administered via DPI or pMDI in patients with asthma (Morice et al 2006; Morice et al 2007a; Morice et al 2007b). In patients with moderate to severe persistent asthma previously receiving ICS therapy, BUD/FM administered together via a pMDI demonstrated similar asthma control as BUD pMDI plus FM DPI administered together via separate inhalers. The therapy also provided significantly greater asthma control compared with BUD pMDI alone or

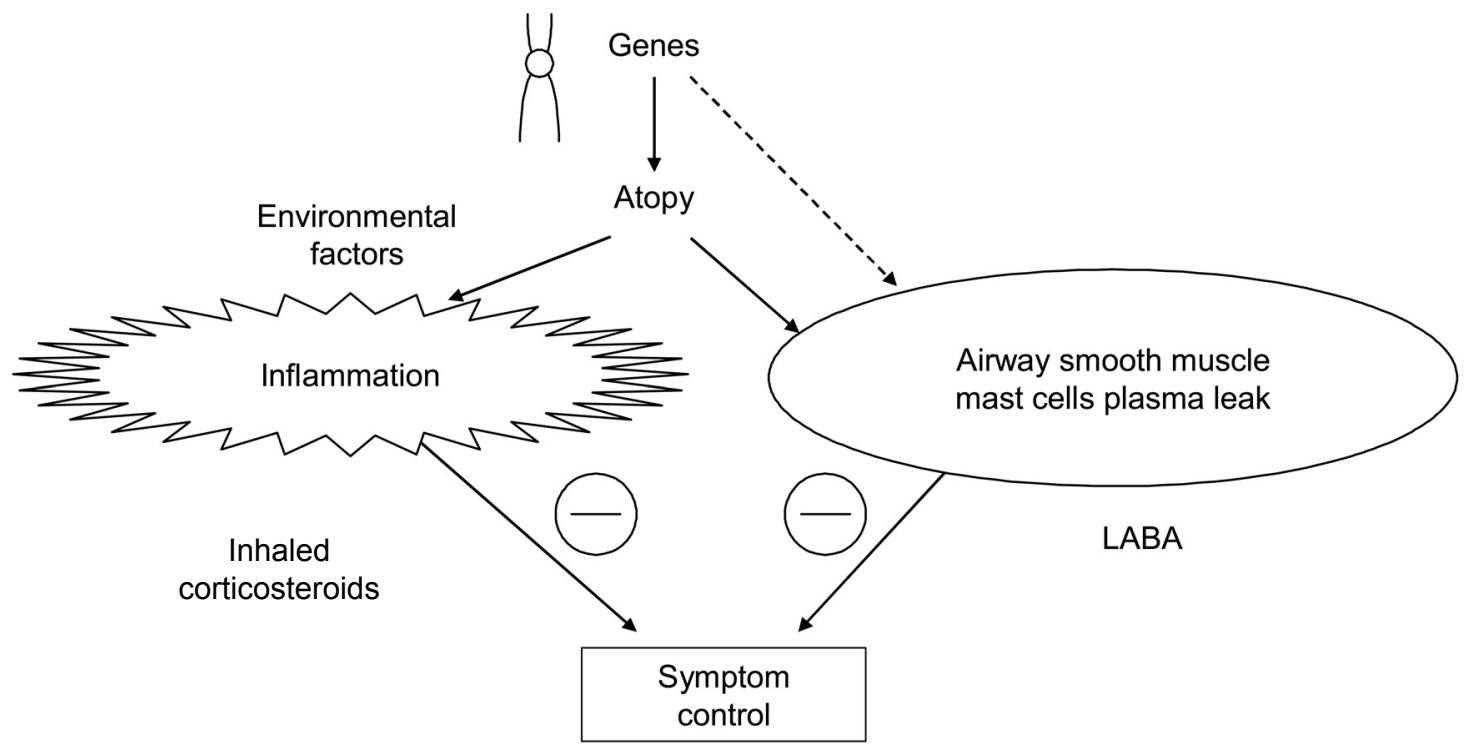

Figure 2 Complementary effects of the long-acting $\beta_{2}$-adrenergic agonists (LABA) and inhaled corticosteroids on the pathophysiologic events underlying asthma. Reproduced with permission from Barnes PJ. 2002. Scientific rationale for inhaled combination therapy with long-acting $\beta_{2}$-agonists and corticosteroids. Eur Respir J, 19:182-91. Copyright 2002 (c) European Respiratory Society Journals Ltd. 
FM DPI alone (Noonan et al 2006). Additionally, BUD/FM pMDI demonstrated significantly increased pulmonary function versus its monocomponents in patients with mild to moderate persistent asthma previously treated with ICSs (Corren et al 2007).

The proprietary formulations of BUD/FM and FP/SAL are available as fixed doses of the LABA component, with different dose levels of the ICS component, which is useful for patients needing to adjust the dose of corticosteroid. A randomized, controlled study demonstrated that patients stabilized on a high dose of BUD alone could step down to low-dose therapy without loss of symptom or lung function control (Foresi et al 2000). Furthermore, this study showed that use of a high dose of BUD at the onset of an exacerbation was associated with additional clinical benefit. Another randomized study showed that as-needed use of FM increased the time to the first severe asthma exacerbation compared with standard rescue therapy (Tattersfield et al 2001).

These findings prompted studies to assess whether the BUD/FM combination inhaler was beneficial when used both as regular maintenance therapy and as-needed reliever therapy for patients needing additional asthma control (O'Byrne et al 2005; Vogelmeier et al 2005; Rabe et al 2006; Bousquet et al 2007; Kuna et al 2007). Maintenance and as-needed reliever therapy is possible with the BUD/FM combination inhaler because FM has an onset of bronchodilator action within the first minute (van der Woude et al 2004) with a similar efficacy and safety to salbutamol in patients with asthma (Pauwels et al 2003; Balanag et al 2006). The contributions of BUD and FM administered as needed were demonstrated in a study in which patients received BUD/FM (160/4.5 $\mu \mathrm{g} \times 1$ inhalation twice daily) as maintenance therapy plus either terbutaline $(0.4 \mathrm{mg}), \mathrm{FM}(4.5 \mu \mathrm{g})$, or BUD/FM $(160 / 4.5 \mu \mathrm{g})$ for as-needed rescue medication (Rabe et al 2006). Patients who used as-needed BUD/FM had a significantly longer time to the first severe exacerbation and a significantly lower rate of severe exacerbations versus patients who used as-needed FM or terbutaline. As-needed FM also significantly increased the time to the first severe exacerbation and reduced the rate of severe exacerbations versus as-needed terbutaline.

In a study evaluating BUD/FM as maintenance and reliever therapy, maintenance treatment with fixed-dose BUD/FM DPI 80/4.5 $\mu \mathrm{g}$ (administered as 1 inhalation twice daily) or BUD $320 \mu \mathrm{g}$ (administered as 1 inhalation twice daily), both with as-needed SABA, was compared with maintenance BUD/FM 80/4.5 $\mu \mathrm{g}$ twice daily plus additional inhalations as needed (O'Byrne et al 2005). The BUD/FM maintenance plus reliever regimen resulted in significantly improved symptom control, pulmonary function, and reduced rates of severe exacerbations and related complications (Figure 3) than either of the fixed-dose plus as-needed SABA regimens (O'Byrne et al 2005). Another study further demonstrated that maintenance and reliever treatment with BUD/FM (160/4.5 $\mu \mathrm{g} \times 2$ inhalations twice daily then titrated, plus additional inhalations as needed) provided similar improvements in pulmonary function with a reduced risk of exacerbations when compared with titrated fixeddose FP/SAL (250/50 $\mu \mathrm{g}$ twice daily then titrated) plus asneeded SABA (Vogelmeier et al 2005). Kuna et al (2007) demonstrated that treatment with BUD/FM, when used as both maintenance $(160 / 4.5 \mu \mathrm{g} \times 1$ inhalation twice daily $)$ and reliever therapy, significantly increased the time to the first severe exacerbation, reduced the rate of severe exacerbations, and reduced the overall ICS dose compared with treatment with higher doses of fixed-dose FP/SAL $(125 / 25 \mu \mathrm{g} \times 2$ inhalations twice daily) or fixed-dose BUD/FM $(320 / 9 \mu \mathrm{g} \times 1$ inhalation twice daily) plus as-needed SABA. Improvements in pulmonary function and asthma symptom-control measures were similar among treatments.

In addition, a recent study compared the efficacy of BUD/FM as maintenance and reliever therapy $(160 / 4.5 \mu \mathrm{g} \times 2$ inhalations twice daily plus as-needed inhalations) with sustained high-dose FP/SAL (500/50 $\mu$ g twice daily plus SABA) for 6 months in patients with uncontrolled asthma (Bousquet et al 2007). BUD/FM as maintenance and reliever therapy significantly reduced the number of total exacerbations and exacerbations requiring hospitalizations/emergency department treatment with significantly less ICS exposure compared with sustained high-dose FP/SAL plus SABA. No differences in the time to the first severe exacerbation, pulmonary function, or asthma symptoms between treatments, however, were observed (Bousquet et al 2007).

In the US, the Food and Drug Administration (FDA) has required "black box" warnings in the prescribing information for all LABA products, including FP/SAL and BUD/FM combination therapy. It is recommended that LABAs only be used in patients with asthma not adequately controlled on other asthma controller medication (eg, low- to medium-dose ICSs). This safety warning is based on a large ( $\mathrm{N}=26,355)$, placebo-controlled trial, which demonstrated that treatment with SAL pMDI $42 \mu \mathrm{g}$ twice daily (Serevent ${ }^{\circledR}$; Glaxo Wellcome, Middlesex, UK) resulted in an increase in asthmarelated deaths compared with placebo $(13 / 13,176$ patients and 3/13,179 patients, respectively) (Nelson et al 2006). A retrospective evaluation of these data suggested that the increased risk of asthma-related death was primarily in 


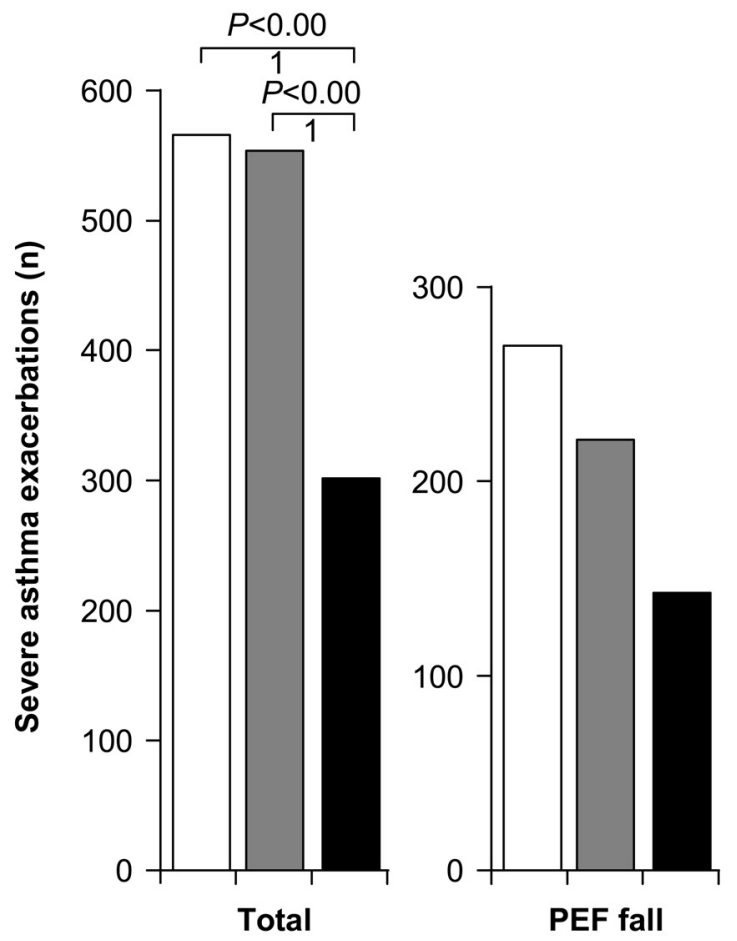

\author{
$\square$ BUD + SABA \\ $\square$ BUD/FM + SABA \\ BUD/FM maintenance + relief
}

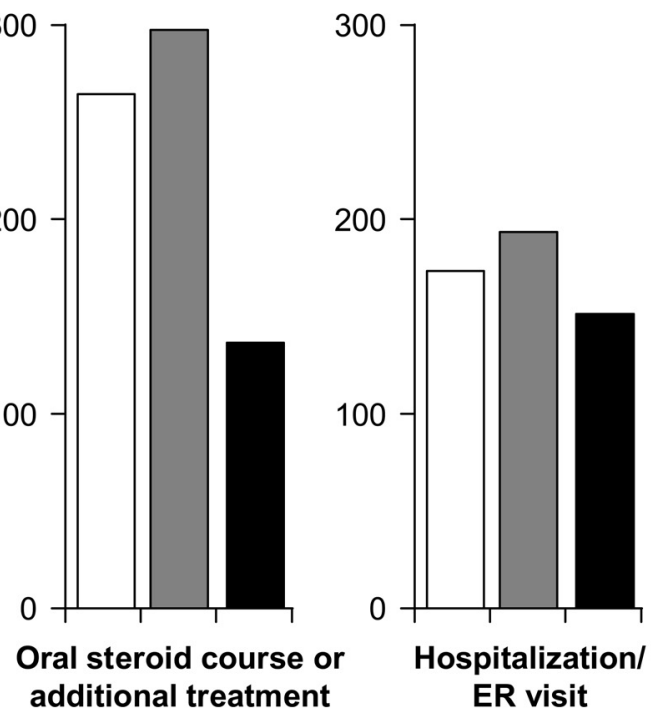

Figure 3 Reduced rates of severe asthma exacerbations and exacerbation subtypes associated with budesonide/formoterol maintenance plus reliever therapy (BUD/FM maintenance + relief) compared with a fixed-dose regimen of either BUD/FM plus a short-acting $\beta_{2}$-adrenergic agonist (BUD/FM + SABA) or budesonide monotherapy plus a SABA (BUD + SABA). Reproduced with permission from O'Byrne PM, Bisgaard H, Godard PP, et al. 2005. Budesonide/formoterol combination therapy as both maintenance and reliever medication in asthma. Am J Respir Crit Care Med, I7I:I29-36. Copyright 2005 (C) American Thoracic Society.

Abbreviations: PEF, peak expiratory flow; ER, emergency room.

those who reported using a LABA but not an ICS, at baseline (Nelson 2006). Moreover, a recent review of 69 trials of patients treated with FM $(n=50,549 ; 94 \%$ prescribed ICS $)$ showed that FM was not associated with increased asthmarelated deaths or serious adverse events (Sears et al 2007). These studies, as well as earlier LABA data showing a lack of anti-inflammatory properties and a lack of efficacy as monotherapy (Nelson 2006), support that LABAs should be administered in combination with an ICS as recommended in the NAEPP and GINA guidelines (GINA 2007; NAEPP 2007).

In summary, fixed-dose combinations of ICS/LABA have recently become the standard of care for patients who are symptomatic on ICS monotherapy. Emerging research suggests additional clinical benefit for BUD/FM maintenance and reliever therapy. Use of BUD/FM as both rescue and maintenance therapy has gained acceptance outside of the US (GINA 2007), where the BUD/FM DPI has been available for more than 6 years.

\section{Anti-lgE therapy}

Omalizumab (Xolair ${ }^{\circledR}$; Genentech Inc, San Francisco, CA, USA) is a relatively new addition to the asthma treatment armamentarium. This agent is a humanized monoclonal antibody that binds to the Fc portion of circulating $\operatorname{IgE}$ antibody on mast cells and basophils, desensitizing mast cells to allergens. The mast cell-stabilizing effect of omalizumab blocks the release of inflammatory mediators in the lung and reduces IgE levels in response to allergen exposure (Chang and Shiung 2006; Corry and Kheradmand 2006; Strunk and Bloomberg 2006).

The guidelines recommend consideration of adjunctive omalizumab treatment at steps 5 or 6 of care for patients at least 12 years of age who have allergies and severe persistent asthma not controlled on high-dose ICS/LABA therapy (GINA 2007; NAEPP 2007). Findings from placebo-controlled trials in adults, adolescents, or children with moderate to severe persistent asthma demonstrate that the addition of subcutaneously administered omalizumab to an existing regimen of high-dose ICS reduced the rate of exacerbations and enabled ICS dose reductions (Busse et al 2001; Milgrom et al 2001; Solèr et al 2001; Humbert et al 2005). In another placebo-controlled study of patients with severe asthma, omalizumab was not associated with a statistically significant reduction in the exacerbation rate (mean number of asthma exacerbations per patient in the corticosteroid-reduction 
phase: placebo 0.34, omalizumab 0.19), but the ICS doses needed to achieve control were significantly reduced (Holgate et al 2004).

In summary, treatment with omalizumab generally is reserved for patients unresponsive to standard ICS therapy who have documented allergic asthma and a serum IgE level between $30 \mathrm{IU}$ and $700 \mathrm{IU}$ (Marcus 2006). Omalizumab is a considerably more costly treatment than other available asthma treatments, ranging in price from US\$6,000 to US $\$ 37,000$ per year (Marcus 2006). More widespread use of omalizumab will likely not occur until cost-effectiveness studies demonstrate meaningful cost avoidance (Miller and Reeves 2005; Marcus 2006).

\section{Future treatments}

Adherence to long-term therapy is an important consideration in the treatment of any chronic disease, and asthma is no exception. A meta-analysis of 76 heterogeneous studies that included electronic monitoring data on medication adherence demonstrated an inverse linear relationship between dosing frequency and rates of adherence (Claxton et al 2001). The need to simplify therapy and improve medication adherence has fostered the search for novel means of administering existing therapies. Research on new molecular entities with improved pharmacokinetic profiles compared with current medications within existing therapeutic classes is one focus of recent drug development. Another important focus of ongoing drug development efforts revolves around finding therapies that target specific events in the inflammatory pathway.

\section{ICS monotherapy}

Ciclesonide (Alvesco ${ }^{\circledR}$; ALTANA Pharma AG, Bad Homburg v.d.H. Germany), a novel corticosteroid prodrug that can be administered on a once-daily dosing schedule, has no intrinsic anti-inflammatory properties. After inhalation, ciclesonide is hydrolyzed in the lung to the pharmacologically active metabolite desisobutyrylciclesonide (Nave 2006). Commercially available in Europe since 2005 , ciclesonide is currently under evaluation by the US FDA. Findings from 2 randomized, double-blind, 12-week, placebo-controlled trials in patients with mild to moderate persistent asthma demonstrated that ciclesonide doses of 80,160 , and $320 \mu \mathrm{g}$ once daily significantly improved pulmonary function and asthma symptoms and reduced albuterol use compared with placebo (Pearlman et al 2005). A systematic review of limited comparative phase 2 studies concluded that ciclesonide was as effective as BUD or FP, but the available studies were not sufficient to determine whether ciclesonide was less likely to suppress hypothalamic-pituitary-adrenal axis function (Dyer et al 2006). In recent noninferiority studies of patients with mild to moderate asthma, ciclesonide $320 \mu \mathrm{g}$ once daily was similar to twice-daily BUD $200 \mu \mathrm{g}$ or FP $200 \mu \mathrm{g}$ in improving pulmonary function, controlling asthma symptoms, and reducing the need for rescue bronchodilators (Hansel et al 2006; Boulet et al 2007). The only apparent differences among the ICSs in their adverse event profiles was a significantly higher frequency of oral candidiasis with FP versus ciclesonide (9 vs 0 cases) (Boulet et al 2007) and a significant decrease from baseline in urinary cortisol concentrations for BUD (400 $\mu \mathrm{g} /$ day) versus ciclesonide (Hansel et al 2006). Further long-term studies are still needed to determine if any clinically relevant long-term efficacy or safety advantages exist. A novel submicron particle suspension of BUD for nebulization (Unit Dose Budesonide [UDB]; MAP Pharmaceuticals Inc., Mountain View, CA) recently has been developed for the treatment of asthma. A randomized, double-blind, active-controlled, single-dose, crossover study in healthy volunteers $(n=16)$ evaluated the pharmacokinetics and safety of UDB administered at three different strengths $(0.06 \mathrm{mg}, 0.12 \mathrm{mg}$, and $0.24 \mathrm{mg} / 2 \mathrm{~mL}$ ) versus budesonide inhalation suspension (BIS) $0.25 \mathrm{mg} / 2 \mathrm{~mL}$ (Pulmicort Respules ${ }^{\circledR}$; AstraZeneca, Wilmington, DE, USA). UDB was well tolerated in healthy adults. UDB $0.24 \mathrm{mg}$ had a significantly greater $\mathrm{C}_{\max }$ compared with BIS $0.25 \mathrm{mg}$. In addition, $\mathrm{T}_{\max }$ was significantly greater for all three doses of UDB compared with BIS. Thus, UDB is absorbed more rapidly than BIS (Bosco et al 2007). The clinical significance of this finding is unknown; larger clinical trials in adults and pediatric patients with asthma have not been reported.

\section{Combination ICS/LABA therapy}

The focus of future development for ICS/LABA therapy is on once-daily dosing with a 24-hour LABA and a LABA with a rapid onset. In the US, the currently available fixed-dose ICS/LABA inhalers are approved for administration twice daily. Although the ICSs BUD and mometasone have shown efficacy when administered once daily, currently available LABAs are usually administered twice daily (NAEPP 2007). Once-daily administration of BUD/FM DPI was investigated in a double-blind, active-control study in 523 patients whose asthma was not fully controlled on ICS alone (Buhl et al 2003). This study compared once-daily dosing of BUD/ FM 160/4.5 $\mu \mathrm{g} \times 2$ inhalations with twice-daily dosing of 
BUD/FM 160/4.5 $\mu \mathrm{g} \times 1$ inhalation or once-daily dosing of BUD $400 \mu \mathrm{g} \times 1$ inhalation. Each treatment resulted in the same total daily dose of budesonide or formoterol. Compared with BUD alone, the fixed-dose combination of ICS/LABA resulted in significant improvements in pulmonary function (Figure 4), asthma symptoms, and days free from asthma symptoms or rescue SABA regardless of dosing schedule. No significant differences in asthma control days were observed between the once-daily and twice-daily BUD/FM dosage groups.

Other ICS/LABA combinations are being evaluated for administration from one single inhaler. For example, a fixeddose combination inhaler of ciclesonide and FM is currently in phase 2 clinical trial evaluation for twice-daily administration (ClinicalTrials.gov 2007a). In addition, twice-daily dosing of a mometasone/FM combination inhaler (ScheringPlough) is in phase 3 clinical trials (ClinicalTrials.gov 2007b). Several phase III clinical trials of fluticasone/FM pMDI (FlutiForm ${ }^{\mathrm{TM}}$; SkyePharma/Abbott) are recruiting pediatric and adult patients with mild, moderate, and severe asthma (ClinicalTrials.gov 2007c). Although mometasone is a marketed ICS, indacaterol is a new LABA that has demonstrated sustained 24-hour bronchodilation (Beeh et al 2007). A once-daily fixed-dose ICS/LABA combination inhaler of mometasone/indacaterol is under development using the Twisthaler ${ }^{\circledR}$ inhalation device (Schering-Plough Corporation 2006).

\section{Immunotherapy}

Immunotherapies target specific elements of asthma pathophysiology. Several different immunotherapeutic approaches are being investigated for the treatment of asthma. Current research includes agents used to treat either atopic or inflammatory disease states (eg, rheumatoid arthritis).

The role of allergen-specific immunotherapy in the treatment of asthma has been extensively studied. A systematic review of 75 trials demonstrated that allergen-specific intradermal or subcutaneous immunotherapy (SCIT) for asthma reduced asthma symptoms and medication use and improved bronchial hyper-reactivity (Abramson et al 2003). Moreover, a recent long-term trial demonstrated that a 3-year course of SCIT given to children and adolescents with grass and/or birch pollen allergy resulted in clinical benefit and possible prevention of the development of asthma 7 years after therapy (Jacobsen et al 2007). The new NAEPP guidelines recommend consideration of SCIT at steps 2 to 4 for patients aged 5 years and older who have allergic asthma (NAEPP 2007). However, the

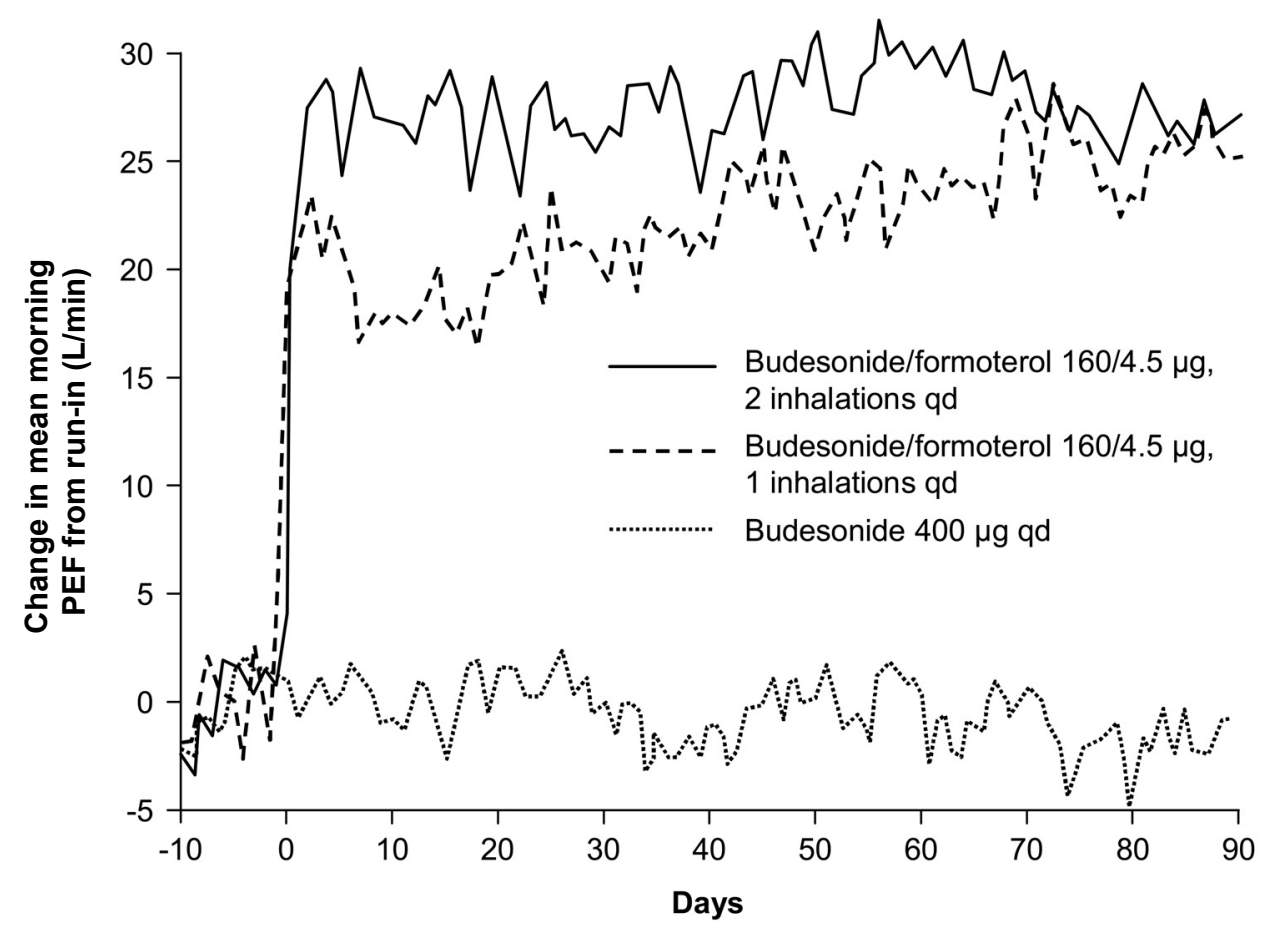

Figure 4 Daily change in mean morning peak expiratory flow (PEF) achieved with once-daily budesonide/formoterol (I60/4.5 $\mu$ g; two inhalations), twice-daily budesonide/ formoterol (160/4.5 $\mu$ g; one inhalation), or once-daily budesonide ( $400 \mu \mathrm{g})$. Reproduced with permission from Buhl R, Creemers JP,VondraV, et al. 2003. Once-daily budesonide/ formoterol in a single inhaler in adults with moderate persistent asthma. Respir Med, 97:323-30. Copyright (C) 2003 Elsevier Ltd. 
GINA guidelines state that specific immunotherapy only be considered if strict environmental avoidance and pharmacologic intervention have been unsuccessful at controlling the patient's asthma (GINA 2007).

Sublingual immunotherapy (SLIT) is being considered as a possible alternative to the subcutaneous route of administration (Passalacqua et al 2004). Although it is gaining acceptance for treatment of atopic disorders, such as allergic rhinitis, SLIT of allergen extracts represents a new and novel treatment for children with allergic asthma (Sopo et al 2004). In a systematic review of SLIT using house dust mite, olive pollen, wall pellitory (Parietaria) pollen, and grass pollen, Sopo et al (2004) concluded that only SLIT with house dust mite resulted in low to modest clinical benefit in children with mild to moderate persistent asthma sensitized to this allergen. However, a different systematic review of 25 studies concluded that SLIT had a modest beneficial effect on asthma in terms of severity reduction (Calamita et al 2006). Another study showed that children with hay fever to grass pollen who were treated with SLIT for 3 years had improved allergic rhinitis symptoms and reduced development of seasonal asthma compared with children treated with standard symptomatic therapy (Novembre et al 2004). These preliminary results with SLIT for asthma treatment and prevention are promising; however, additional studies are needed on effective dose, treatment schedules, and duration of treatment with a specific allergy extract in different patient populations (Cox et al 2006).

Rush immunotherapy (RIT) is a procedure that enables rapid desensitization of allergic patients through repeated injections of allergenic extract over a short time period (Cox 2006). Using this technique, the therapeutic maintenance dose can be achieved in as little as 1-3 days compared with 3-6 months using conventional immunotherapy (Cox 2006). RIT has demonstrated efficacy for several inhalant allergens, including dust mite (Kohno et al 1998), pollen (Movérare et al 2001), and mold (Horst et al 1990), although the high incidence of systemic reactions reported with RIT has limited its widespread use (Nelson 2007). In a study evaluating the effect of omalizumab treatment before initiating RIT on systemic reactions in patients with ragweed allergic rhinitis, fewer and less severe adverse events, including anaphylactic reactions, were observed with omalizumab pretreatment compared with RIT alone (Casale et al 2006). Further studies are needed to determine the optimal timing and dosing of omalizumab pretreatment in RIT protocols in different patient populations, including those with allergic asthma; however, the results from these studies suggest that RIT may hold promise in the future as a convenient immunotherapy option in allergic patients.

\section{Biologic modifiers}

Tumor necrosis factor-alpha (TNF- $\alpha$ ) is an inflammatory cytokine produced by mast cells and found in the airways of patients with asthma (Rouhani et al 2005). Several small pilot studies suggest a possible role for blocking the effects of TNF- $\alpha$ in patients with severe, refractory asthma. The TNF- $\alpha$ antagonist, etanercept (Enbrel ${ }^{\circledR}$; Immunex Corporation, Thousand Oaks, CA, USA), administered $25 \mathrm{mg}$ subcutaneously twice weekly for 2 weeks, was evaluated in a randomized, placebo-controlled trial of patients with mild to moderate allergic asthma $(n=26)$ (Rouhani et al 2005). No appreciable clinical effect on measures of airway hyperresponsiveness was demonstrated, and the trial was stopped early because one patient developed transient left-sided hemiplegia. In contrast, a placebo-controlled crossover study of patients with refractory asthma $(n=10)$ demonstrated that a twice-weekly course of etanercept $25 \mathrm{mg}$ for 10 weeks was significantly more effective than placebo in improvement in pulmonary function, asthma symptoms, and quality of life (Berry et al 2006). The humanized monoclonal antibody against TNF- $\alpha$, infliximab (Remicade ${ }^{\circledR}$; Centocor, Malvern, PA, USA), was evaluated in a placebo-controlled trial of patients with moderately severe asthma $(n=38)$ (Erin et al 2006). Infliximab was administered as a $5-\mathrm{mg} / \mathrm{kg}$ intravenous infusion at weeks 0,2 , and 6. No significant differences were observed between infliximab and placebo in the change from baseline for morning PEF (primary endpoint). However, infliximab treatment resulted in significantly greater improvements in the diurnal variation in PEF and reduced rates of exacerbations compared with placebo. These preliminary findings suggest that larger trials are needed to confirm the efficacy of therapies directed against TNF- $\alpha$.

Tacrolimus is a calcineurin inhibitor used orally as an immunosuppressive agent in organ transplantation (Prograf ${ }^{\circledR}$; Astellas Pharma US, Inc., Deerfield, IL, USA) and topically (Protopic ${ }^{\circledR}$; Astellas) in dermatologic conditions, such as psoriasis. The putative mechanism of action of tacrolimus in asthma is inhibition of type $2 \mathrm{~T}$ helper (Th2) cytokines and subsequent improvement in airway inflammation (Matsuo et al 2001; Saeki et al 2004). A phase 2 trial of aerosolized tacrolimus in patients with asthma recently has been completed (ClinicalTrials.gov 2007d), but the results are not yet published.

Anti-interleukin-5 (IL-5) is another biologic modifier under investigation in clinical trials. Mepolizumab is one 
monoclonal antibody against IL-5 that reduces eosinophils in the airways and periphery (Büttner et al 2003; MenziesGow et al 2003), but a small, phase 1 trial $(n=24)$ failed to show a salient effect on airway hyper-responsiveness or allergen-induced bronchoconstriction in patients with mild allergic asthma (Leckie et al 2000). In a small, dose-ranging study $(\mathrm{n}=26)$, another monoclonal anti-IL-5 antibody (SCH55700) produced modest improvements in lung function in patients with severe asthma receiving high-dose ICS or oral corticosteroid therapy, but no change in other clinical endpoints versus placebo (Kips et al 2003). Determination of a possible role of antibodies directed against IL-5 awaits the results of further clinical trials.

\section{Pharmacogenetics}

In the future, pharmacogenetics may offer the opportunity to individualize asthma treatment based on associations between a particular genetic polymorphism and a predicted response to treatment (Wechsler 2006). Some pharmacogenetic studies have suggested that a homozygous arginine (Arg) genotype at amino acid position 16 of the $\beta_{2}$-adrenergic receptor is associated with worsening asthma clinical outcomes in patients receiving the SABA albuterol (Taylor et al 2000; Israel et al 2000; Israel et al 2004) or the LABA salmeterol (Weschsler et al 2006). However, studies with LABAs show conflicting results (Dorinsky et al 2004; Bleecker et al 2006; Hancox et al 1998; Bleecker et al 2007; Goldman et al 2007). For example, two studies with the largest homozygous Arg population to date (Arg/Arg, $n=430$ ) demonstrated that genotype had no effect on the percentage of patients experiencing severe exacerbations or other clinical outcomes in response to the LABA FM when administered with the ICS BUD (Bleecker et al 2007). Based on these data, a homozygous Arg/Arg at amino acid position 16 of the $\beta_{2}$-adrenergic receptor does not appear to affect treatment response to LABAs.

Other pharmacogenetic variations have been identified. For example, studies have suggested that the transcription factor T-bet gene (TBX21) may be involved in the effect of ICS therapy on airway responsiveness in asthma (Tantisira et al 2004; Raby et al 2006). Heterogenetic response to treatment with LTMs has been reported, which may be attributable to polymorphisms in genes that encode proteins in the LT pathway (Lima et al 2006; Lima 2007). For example, one study showed that response to treatment with montelukast may be influenced by particular polymorphisms in the cysteinyl leukotriene receptor 2, CYSLTR2, and arachidonate 5-lipoxygenase, ALOX5, genes (Klotsman et al 2007).
Additionally, some pharmacogenetic studies on asthma have demonstrated that polymorphisms in the prostanoid receptor genes PTGER2, PTGER3, PTGER4, PTGIR, and TBXA2R influence the pathogenesis of aspirin-intolerant asthma (Kim et al 2007).

Asthma is a variable disease with individual variation in symptoms and treatment responses. Although none of the genotypes in isolation explain the degree of patient variability in drug response (NAEPP 2007), future pharmacogenetic studies may identify additional genetic polymorphisms that affect individual treatment response and further elucidate the mechanisms involved in the genetic response to treatment. Pharmacogenetics may be used in the future to predict a patient's response to treatment based on a patient's genotype and allow for individualized treatment (Wechsler 2006; NAEPP 2007).

\section{Gene therapy}

Gene-based vaccines may have a role in immunomodulation for patients who have corticosteroid-resistant asthma or severe asthma requiring systemic corticosteroid therapy (Kolb et al 2006). It has been postulated that gene therapies targeting the Th2 cell pathway involved in chronic airway inflammation may be beneficial in the treatment of asthma (Kolb et al 2006; Wang et al 2007). Results from Hogan et al (1998) demonstrated suppression of the Th2 response to aerosolized ovalbumin in mice after gene transfer of IL-12, thus inhibiting allergic airways disease. Moreover, overexpression of IL-12 restored local antiviral immunity, which may be relevant in patients who have viral-induced exacerbations (Hogan et al 1998). Another study in mice showed that allergen-induced airway hyperresponsiveness was significantly inhibited by gene transfer of IFN- $\gamma$ (Dow et al 1999). In addition, a study by Mathieu et al (1999) suggested a potential role for gene therapy in corticosteroid-resistant asthma. In vitro gene transfer of the glucocorticocoid receptor gene repressed nuclear factor- $\kappa \mathrm{B}$ activities even without exogenous corticosteroids; thus, delivery of this gene may restore corticosteroid sensitivity in corticosteroid-resistant patients (Mathieu et al 1999).

\section{Conclusion}

Current treatment strategies approach asthma as a relatively homogeneous disease, addressing inflammation, bronchoconstriction, and airway hyper-responsiveness using corticosteroids, SABAS, LABAS, LTMs, and other pharmacologic agents. Although significant inroads to better patient outcomes have been achieved using currently available 
treatments, barriers to effective asthma control continue to exist, in part because of variability in treatment response and issues with treatment adherence.

The most recent asthma management guidelines, put forth by the NAEPP and GINA in 2007, provide updated recommendations in an effort to optimize asthma treatment and standardize approaches to diagnosis and assessment, all while retaining a focus on the individual. Recommendations include an initial evaluation of asthma severity followed by continued monitoring of asthma control at follow-up visits, factoring in the element of treatment responsiveness. In addition, the guidelines outline a step-wise approach to managing asthma, providing treatment recommendations for each step based on the most recent efficacy and tolerability data. These recommendations are meant to assist clinicians in making treatment decisions; however, health care providers also must consider a variety of additional factors, including the patient's asthma history and the likelihood of a patient to adhere to a particular treatment.

The goal of many newly available or emerging treatment approaches has been to provide effective, safe, and simple treatment options for patients with asthma. Other emerging treatments combine existing agents that have unique and complementary anti-inflammatory and bronchodilatory actions, such as the combination of FP/SAL administered via HFA pMDI and BUD/FM administered via DPI. BUD/FM has demonstrated a fast onset of action and effectiveness as maintenance and reliever therapy. This approach allows therapy to be tailored to an individual's changing needs. BUD/ FM as maintenance and reliever therapy is currently only available outside of the US. Other ICS/LABA combination therapies that are in development and offer promise include the combinations of ciclesonide/FM, mometasone/FM, and mometasone/indacaterol, all of which have rapidly acting LABAs. The monoclonal antibody therapy omalizumab, which is recommended in combination with high-dose ICS plus LABA by the recent NAEPP and GINA guidelines, offers a unique approach to treating patients with severe allergic asthma that is not controlled with high-dose ICS plus LABA. The novel immunotherapy anti-TNF- $\alpha$ antibody etanercept also is being investigated for the treatment of patients with severe asthma.

The variety of existing and emerging treatment options that address multiple facets of asthma offer promise for reducing the substantial health care and economic burden of asthma. In the near future, the development of more specialized diagnostic tests and the use of more individualized approaches to asthma management will be critical for further improving asthma outcomes. Research is currently underway to better understand the causes of inter- and intra-patient variability in treatment response, focusing on factors, such as obesity, genetic predisposition, and gene-environment interactions. Identification of risk factors that contribute to differential response to treatment will aid clinicians in selecting the optimal treatments for their patients.

\section{Acknowledgments}

The author acknowledges Marissa Buttaro, MPH, Cynthia Gobbel, PhD, and Lisa M. Klumpp, PhD, of Scientific Connexions, Newtown, PA, for providing medical writing support funded by AstraZeneca LP.

\section{Abbreviations}

Arg, arginine; BIS, BUD inhalation suspension; BUD, budesonide; FeNO, fractional concentration of exhaled NO; $\mathrm{FEV}_{1}$, forced expiratory volume in 1 second; FM, formoterol; FP, fluticasone; GINA, Global Initiative for Asthma; ICS, inhaled corticosteroid; IgE, immunoglobulin E; IL-5, interleukin-5; LABA, long-acting $\beta 2$-adrenergic agonist; LTM, leukotriene modifier; LTRA, leukotriene receptor antagonist; NAEPP, National Asthma Education and Prevention Program; NO, nitric oxide; PEF, peak expiratory flow; pMDI, pressurized metered-dose inhaler; SABA, short-acting $\beta 2$-adrenergic agonist; SAL, salmeterol; SCIT, subcutaneous immunotherapy; SLIT, sublingual immunotherapy; T helper, Th; TNF- $\alpha$, tumor necrosis factor-alpha; UDB, unit dose budesonide.

\section{References}

Abramson MJ, Puy RM, Weiner JM. 2003. Allergen immunotherapy for asthma [review]. Cochrane Database Syst Rev, 4:CD001186.

Alving K, Janson C, Nordvall L. 2006. Performance of a new hand-held device for exhaled nitric oxide measurement in adults and children. Respir Res, 7:67.

[ALA] American Lung Association. 2006. Trends in asthma morbidity and mortality. American Lung Association Epidemiology and Statistics Unit Research and Program Services [online]. Accessed 31 May 2007. URL: http://www.lungusa.org/atf/cf/\%7B7A8D42C2-FCCA-4604-8ADE7F5D5E762256\%7D/ASTHMA06FINAL.PDF.

[ATS] American Thoracic Society. 2006. ATS workshop proceedings: Exhaled nitric oxide and nitric oxide oxidative metabolism in exhaled breath condensate. Proc Am Thorac Soc, 3:131-45.

Asmanex Twisthaler $220 \mathrm{mcg}$ [package insert]. Kenilworth, NJ: Schering Corporation; 2005.

Balanag VM, Yunus F, Yang P-C, Jorup C. 2006. Efficacy and safety of budesonide/formoterol compared with salbutamol in the treatment of acute asthma. Pulm Pharmacol Ther, 19:139-47.

Barnes PJ. 2002. Scientific rationale for inhaled combination therapy with long-acting $\beta_{2}$-agonists and corticosteroids. Eur Respir J, 19:182-91.

Bateman ED, Silins V, Bogolubov M. 2001. Clinical equivalence of salmeterol/fluticasone propionate in combination (50/100 $\mu \mathrm{g}$ twice daily) when administered via a chlorofluorocarbon-free metered dose inhaler or dry powder inhaler to patients with mild-to-moderate asthma. Respir Med, 95:136-46. 
Beeh KM, Derom E, Kanniess F, et al. 2007. Indacaterol, a novel inhaled $\beta_{2}$-agonist, provides sustained 24 -h bronchodilation in asthma. Eur Respir J, 29:871-8.

Berry MA, Hargadon B, Shelley M, et al. 2006. Evidence of a role of tumor necrosis factor $\alpha$ in refractory asthma. $N$ Engl J Med, 354:697-708.

Bleecker ER, Yancey SW, Baitinger LA, et al. 2006. Salmeterol response is not affected by $\beta_{2}$-adrenergic receptor genotype in subjects with persistent asthma. J Allergy Clin Immunol, 118:809-16.

Bleecker ER, Postma D, Lawrance R, et al. 2007. Effect of polymorphisms in the $\beta_{2}$-adrenergic receptor gene on response to long-acting $\beta$-agonist therapy. Lancet, in press.

Bosco AP, Shrewsbury SB, Longhi M, et al. 2007. Pharmacokinetics and tolerability of a novel submicron particle formulation of budesonide for nebulized delivery in asthma. Poster K7-A192. Presented at the international conference of the American Thoracic Society, San Francisco, CA, USA.

Boulet L-P, Bateman ED, Voves R, et al. 2007. A randomized study comparing ciclesonide and fluticasone propionate in patients with moderate persistent asthma. Respir Med, 101:1677-86.

Bousquet J, Boulet LP, Peters MJ, et al. 2007. Budesonide/formoterol for maintenance and relief in uncontrolled asthma vs. high-dose salmeterol/fluticasone. Respir Med, [Epub ahead of print].

Buhl R, Creemers JP, Vondra V, et al. 2003. Once-daily budesonide/ formoterol in a single inhaler in adults with moderate persistent asthma Respir Med, 97:323-30.

Busse W, Corren J, Lanier BQ, et al. 2001. Omalizumab, anti-IgE recombinant humanized monoclonal antibody, for the treatment of severe allergic asthma. $J$ Allerg Clin Immunol, 108:184-90.

Büttner C, Lun A, Splettstoesser T, et al. 2003. Monoclonal anti-interleukin-5 treatment suppresses eosinophil but not T-cell functions. Eur Respir $J, 21: 799-803$.

Calamita Z, Saconato H, Pelá AB, et al. 2006. Efficacy of sublingual immunotherapy in asthma: systematic review of randomized-clinical trials using the Cochrane Collaboration method. Allergy, 61:1162-72.

Casale TB, Busse WW, Kline JN, et al. 2006. Omalizumab pretreatment decreases acute reactions after rush immunotherapy for ragweed-induced seasonal allergic rhinitis. $J$ Allergy Clin Immunol, 117:134-40.

Chang TW, Shiung Y-Y. 2006. Anti-IgE as a mast cell-stabilizing therapeutic agent. J Allergy Clin Immunol, 117:1203-12.

Claxton AJ, Cramer J, Pierce C. 2001. A systematic review of the associations between dose regimens and medication compliance. Clin Ther, 23:1296-1310.

ClinicalTrials.gov. 2007a. Safety and tolerability of ciclesonide and formoterol fumarate inhaled once daily in patients with asthma (18 to 75 y) (BY9010/M1-506). Accessed 29 June 2007. URL: http://www. clinicaltrials.gov/ct/show/NCT00314509?order=1.

ClinicalTrials.gov. 2007b. Effects of mometasone furoate/formoterol combination versus mometasone furoate alone in persistent asthmatics (Study P04431AM1). Accessed 29 June 2007. URL: http://www.clinicaltrials. gov/ct/show/NCT00381485?order=1 Accessed June 29, 2007.

ClinicalTrials.gov. 2007c. Search: Flutiform. Accessed 29 June 2007. URL: http://www.clinicaltrials.gov/ct/search; jsessionid=B86F15C0A8AA0 3232A0528328EF047B5?term=flutiform.

ClinicalTrials.gov. 2007d. A study of the safety and efficacy of tacrolimus inhalation aerosol in subjects with persistent asthma. Accessed 31 May 2007. URL: http://clinicaltrials.gov/ct/show/ NCT00116103? order $=20$.

Corren J, Korenblat PE, Miller CJ, et al. 2007. Twelve-week, randomized, placebo-controlled, multicenter study of the efficacy and tolerability of budesonide and formoterol in one metered-dose inhaler compared with budesonide alone and formoterol alone in adolescents and adults with asthma. Clin Ther, 29:823-43.

Corry DB, Kheradmand F. 2006. Control of allergic airway inflammation through immunomodulation. J Allergy Clin Immunol, 117:S461-4.

Cox L. 2006. Accelerated immunotherapy schedules: review of efficacy and safety. Ann Allergy Asthma Immunol, 97:126-38.
Cox LS, Linnemann DL, Nolte H, et al. 2006. Sublingual immunotherapy: a comprehensive review. J Allergy Clin Immunol, 117:1021-35.

Crompton G. 2006. A brief history of inhaled asthma therapy over the last fifty years. Prim Care Respir J, 15:326-31.

Dahlén B, Malmström K, Nizankowska E, et al. 2002. Improvement of aspirin-intolerant asthma by montelukast, a leukotrienes antagonist. Am J Respir Crit Care Med, 165:9-14.

Dahlén B, Nizankowska E, Szczeklik A, et al. 1998. Benefits from adding the 5-lipoxygenase inhibitor zileuton to conventional therapy in aspirinintolerant asthmatics. Am J Respir Crit Care Med, 157:1187-94.

Dennis SM, Sharp SJ, Vickers MR, et al; for the Therapy Working Group of the National Asthma Task Force and the MRC General Practice Research Framework. 2000. Regular inhaled salbutamol and asthma control: the TRUST randomised trial. Lancet, 355:1675-9.

Dorinsky PM, Yancey SW, Baitinger LA, et al. 2004. Salmeterol response is not affected by beta2-adrenergic receptor genotype in patients with persistent asthma. Chest, 126:722S.

Dow SW, Schwarze J, Heath TD, et al. 1999. Systemic and local interferon gamma gene delivery to the lungs for treatment of allergen-induced airway hyperresponsiveness in mice. Hum Gene Ther, 10:1905-14.

Drazen JM, Israel E, Boushey HA, et al; for the National, Heart, Lung, and Blood Institute's Asthma Clinical Research Network. 1996. Comparison of regularly scheduled with as-needed use of albuterol in mild asthma. N Engl J Med, 335:841-7.

Ducharme FM, Di Salvio F. 2004. Anti-leukotriene agents compared to inhaled corticosteroids in the management of recurrent and/or chronic asthma in adults and children. Cochrane Database Syst Rev, 2:CD002314.

Dyer MJ, Halpin DM, Stein K. 2006. Inhaled ciclesonide versus inhaled budesonide or inhaled beclomethasone or inhaled fluticasone for chronic asthma in adults: a systematic review. BMC Fam Pract, 7:34.

Erin EM, Leaker BR, Nicholson GC, et al. 2006. The effects of a monoclonal antibody directed against tumor necrosis factor- $\alpha$ in asthma. Am J Respir Crit Care Med, 174:753-62.

Foresi A, Morelli MC, Catena E; on behalf of the Italian Study Group. 2000. Low-dose budesonide with the addition of an increased dose during exacerbations is effective in long-term asthma control. Chest, 117:440-6.

Gibson PG, Powell H, Ducharme F. 2005. Long-acting beta2-agonists as an inhaled corticosteroid-sparing agent for chronic asthma in adults and children. Cochrane Database Syst Rev, 4:CD005076.

GINA (Global Initiative for Asthma). 2007. GINA report: Global Strategy for Asthma Management and Prevention. Accessed 29 January 2008. URL: http://www.ginasthma.org.

Greening AP, Ind PW, Northfield M, et al; on behalf of Allen and Hansburys Limited UK Study Group. 1994. Added salmeterol versus higher-dose corticosteroid in asthma patients with symptoms on existing inhaled corticosteroid. Lancet, 344:219-24.

Greenstone IR, Ni Chroinin MN, Masse V, et al. 2005. Combination of inhaled long-acting beta2-agonists and inhaled steroids versus higher dose of inhaled steroids in children and adults with persistent asthma. Cochrane Database Syst Rev, 4:CD005533.

Goldman M, Lawrance R, Ambrose H. 2007. Effect of Gly16Arg $\beta_{2}$ adrenergic receptor variation on response to formoterol administered alone or in combination with budesonide in patients with moderate to severe persistent asthma [abstract 957]. J Allergy Clin Immunol, 119(suppl 1):S244.

Hancox RJ, Sears MR, Taylor DR. 1998. Polymorphism of the $\beta_{2}$-adrenoceptor and the response to long-term $\beta_{2}$-agonist therapy in asthma. Eur Respir J, 11:589-93.

Hansel TT, Benezet O, Kafé H, et al. 2006. A multinational, 12-week, randomized study comparing the efficacy and tolerability of ciclesonide and budesonide in patients with asthma. Clin Ther, 28:906-20.

Hines RN, McCarver DG. 2006. Pharmacogenomics and the future of drug therapy. Pediatr Clin N Am, 53:591-619.

Hogan SP, Foster PS, Tan X, Ramsay AJ. 1998. Mucosal IL-12 gene delivery inhibits allergic airways disease and restores local antiviral immunity. Eur J Immunol, 28:413-23. 
Holgate ST, Bradding P, Sampson AP. 1996. Leukotriene antagonists and synthesis inhibitors: new directions in asthma therapy. J Allergy Clin Immunol, 98:1-13.

Holgate ST, Chuchalin AG, Hébert J, et al. 2004. Efficacy and safety of a recombinant anti-immunoglobulin E antibody (omalizumab) in severe allergic asthma. Clin Exp Allergy, 34:632-8.

Horst M, Hejjaoui A, Horst V, et al. 1990. Double-blind, placebo-controlled rush immunotherapy with a standardized Alternaria extract. $J$ Allergy Clin Immunol, 85:460-72.

Humbert M, Beasley R, Ayres J, et al. 2005. Benefits of omalizumab as add-on therapy in patients with severe persistent asthma who are inadequately controlled despite best available therapy (GINA 2002 step 4 treatment): INNOVATE. Allergy, 60:309-16.

Israel E, Drazen JM, Liggett SB, et al; for the National Heart Lung and Blood Institute's Asthma Clinical Research Network. 2000. The effect of polymorphisms of the $\beta_{2}$-adrenergic receptor on the response to regular use of albuterol in asthma. Am J Respir Crit Care Med, 162:75-80.

Israel E, Chinchilli VM, Ford JG, et al. 2004. Use of regularly scheduled albuterol treatment in asthma: genotype-stratified, randomized, placebocontrolled cross-over trial. Lancet, 364:1505-12.

Jacobsen L, Niggemann B, Dreborg S, et al. 2007. Specific immunotherapy has long-term preventive effect of seasonal and perennial asthma: 10year follow-up on the PAT study. Allergy, 62:943-8.

Kim S-H, Kim Y-K, Park HW, et al. 2007. Association between polymorphisms in prostanoid receptor genes and aspirin-intolerant asthma. Pharmacogenet Genomics, 17:295-304.

Kips J. 2002. Managing a variable disease. Pulmon Pharmacol Therap, 15:485-90.

Kips JC, O’Connor BJ, Langley SJ, et al. 2003. Effect of SCH55700, a humanized anti-human interleukin-5 antibody, in severe persistent asthma: a pilot study. Am J Respir Crit Care Med, 167:1655-9.

Klotsman M, York TP, Pillai SG, et al. 2007. Pharmacogenetics of the 5lipoxygenase biosynthetic pathway and variable clinical response to montelukast. Pharmacogenet Genomics, 17:189-96.

Kolb M, Martin G, Medina M, et al. 2006. Gene therapy for pulmonary diseases. Chest, 130:879-84.

Kohno Y, Minoguchi K, Oda N, et al. 1998. Effect of rush immunotherapy on airway inflammation and airway hyperresponsiveness after bronchoprovocation with allergen in asthma. J Allergy Clin Immunol, 102:927-34

Kuna P, Peters MJ, Manjra AI, et al. 2007. Effect of budesonide/formoterol maintenance and reliever therapy on asthma exacerbations. Int J Clin Pract, 61:725-36.

Lazarus SC, Boushey HA, Fahy JV, et al. 2001. Long-acting $\beta_{2}$-agonist monotherapy vs continued therapy with inhaled corticosteroids in patients with persistent asthma. A randomized controlled trial. JAMA, 285:2583-93.

Lazarus SC, Lee T, Kemp JP, et al. 1998. Safety and clinical efficacy of zileuton in patients with chronic asthma. Am J Mang Care, 4:841-8.

Leckie MJ, ten Brinke A, Khan J, et al. 2000. Effects of an interleukin-5 blocking monoclonal antibody on eosinophils, airway hyper-responsiveness, and the late asthmatic response. Lancet, 356:2144-8.

Lemanske RF, Sorkness CA, Mauger EA, et al. 2001. Inhaled corticosteroid reduction and elimination in patients with persistent asthma receiving salmeterol. A randomized controlled trial. JAMA, 285:2594-603.

Lima JJ. 2007. Treatment heterogeneity in asthma: genetics of response to leukotriene modifiers. Mol Diagn Ther, 11:97-104.

Lima JJ, Zhang S, Grant A, et al. 2006. Influence of leukotriene pathway polymorphisms on response to montelukast in asthma. Am J Respir Crit Care Med, 173: 379-85.

Marcus P. 2006. Incorporating anti-IgE (omalizumab) therapy into pulmonary medicine practice: Practice management implications. Chest, 129:466-74.

Marotta A, Klinnert MD, Price MR, et al. 2003. Impulse oscillometry provides an effective measure of lung dysfunction in 4-year-old children at risk for persistent asthma. J Allergy Clin Immunol, 112:317-22.
Mathieu M, Gougat C, Jaffuel D, et al. 1999. The glucocorticoid receptor gene as a candidate for gene therapy in asthma. Gene Ther, 6:245-52.

Matsuo N, Shimoda T, Mitsuta K, et al. 2001. Tacrolimus inhibits cytokine production and chemical mediator release following antigen stimulation of passively sensitized human lung tissues. Ann Allergy Asthma Immunol, 86:671-8.

Menzies-Gow A, Flood-Page P, Sehmi R, et al. 2003. Anti-IL-5 (mepolizumab) therapy induces bone marrow eosinophil maturational arrest and decreases eosinophil progenitors in the bronchial mucosa of atopic asthmatics. J Allergy Clin Immunol, 111:714-19.

Milgrom H, Berger W, Nayak A, et al. 2001. Treatment of childhood asthma with anti-immunoglobulin E antibody (omalizumab). Pediatrics, 108: E36.

Miller TP, Reeves MJ. 2005. Lack of cost-effectiveness of omalizumab. J Allergy Clin Immunol, 115:429-30.

Miller-Larsson A, Selroos O. 2006. Advances in asthma and COPD treatment: combination therapy with inhaled corticosteroids and long-acting $\beta_{2}$-agonists. Curr Pharm Des, 12:3261-79.

Morice AH, Hochmuth L, Ekelund J, et al. 2006. Comparable long-term safety and efficacy of a novel budesonide/formoterol pressurized metered-dose inhaler versus budesonide/formoterol Turbuhaler ${ }^{\mathbb{E}}$ in adolescents and adults with asthma. Pulm Pharmacol Ther, [Epub ahead of press].

Morice AH, Peterson S, Beckman O, et al. 2007a. Efficacy and safety of a new pressurised metered-dose inhaler formulation of budesonide/formoterol in children with asthma: A superiority and therapeutic equivalence study. Pulm Pharmacol Ther, [Epub ahead of press].

Morice AH, Peterson S, Beckman O, et al. 2007b. Therapeutic comparison of a new budesonide/formoterol pMDI with budesonide pMDI and budesonide/formoterol DPI in asthma. Int $J$ Clin Pract, 61:1874-83.

Movérare R, Vesterinen E, Metso T, et al. 2001. Pollen-specific rush immunotherapy: clinical efficacy and effects on antibody concentrations. Ann Allergy Asthma Immunol, 86:337-42.

NAEPP (National Asthma Education and Prevention Program). 2007. Full report of the Expert Panel: Guidelines for the Diagnosis and Management of Asthma (EPR-3). National Heart, Lung, and Blood Institute. Accessed 25 October 2007. URL: http://www.nhlbi.nih.gov/guidelines/asthma/asthgdln.htm.

Nathan RA, Rooklin A, Schoaf L, et al. 2006. Efficacy and tolerability of fluticasone proprionate/salmeterol administered twice daily via hydrofluoroalkane 134a metered-dose inhaler in adolescent and adult patients with persistent asthma: a randomized, double-blind, placebo-controlled, 12-week study. Clin Ther, 28:73-85.

Nave R, Fisher R, Zech K. 2006. In vitro metabolism of ciclesonide in human lung and liver precision-cut tissue slices. Biopharm Drug Dispos, 27:197-207.

Nelson HS, Weiss ST, Bleecker ER, et al; the SMART study group. 2006. The salmeterol multicenter asthma research trial: A comparison of usual pharmacotherapy for asthma or usual pharmacotherapy plus salmeterol. Chest, 129:15-26.

Nelson HS. 2006. Long-acting beta-agonists in adult asthma: evidence that these drugs are safe. Prim Care Respir J, 15:271-7.

Noonan M, Rosenwasser LJ, Martin P, et al. 2006. Efficacy and safety of budesonide and formoterol in one pressurized metered-dose inhaler in adults and adolescents with moderate to severe asthma: a randomised clinical trial Drugs, 66:2235-54.

Novembre E, Galli E, Landi F, et al. 2004. Coseasonal sublingual immunotherapy reduces the development of asthma in children with allergic rhinoconjunctivitis. J Allergy Clin Immnol, 114:851-7.

O'Byrne PM, Bisgaard H, Godard PP, et al. 2005. Budesonide/formoterol combination therapy as both maintenance and reliever medication in asthma. Am J Respir Crit Care Med, 171:129-36.

Passalacqua G, Guerra L, Pasquali M, et al. 2004. Efficacy and safety of sublingual immunotherapy. Ann Allergy Asthma Immunol, 93:3-12. 
Pauwels RA, Löfdahl C-G, Postma DS, et al; for the Formoterol and Corticosteroids, Establishing Therapy (FACET) International Study Group. 1997. Effect of inhaled formoterol and budesonide on exacerbations of asthma. N Engl J Med, 337:1405-11.

Pauwels RA, Sears MR, Campbell M, et al; on behalf of the RELIEF Study Investigators. 2003. Formoterol as relief medication in asthma: a worldwide safety and effectiveness trial. Eur Resp J, 22:787-94.

Pearlman DS, Berger WE, Kerwin E, et al. 2005. Once-daily ciclesonide improves lung function and is well tolerated by patients with mild-tomoderate persistent asthma. J Allergy Clin Immunol, 116:1206-12.

Pearlman DS, Peden D, Condemi JJ, et al. 2004. Efficacy and safety of fluticasone propionate/salmeterol HFA 134A MDI in patients with mild-to-moderate persistent asthma. J Asthma, 41:797-806.

Petsky HL, Kynaston JA, Turner C, et al. 2007. Tailored interventions based on sputum eosinophils versus clinical symptoms for asthma in children and adults. Cochrane Database Syst Rev, 18:CD005603.

Pulmicort Flexhaler $180 \mathrm{mcg}$ and $90 \mathrm{mcg}$ [package insert]. Wilmington, DE: AstraZeneca; 2007.

Rabe KF, Atienza T, Magyar P, et al. 2006. Effect of budesonide in combination with formoterol for reliever therapy in asthma exacerbations: a randomised, controlled, double-blind study. Lancet, 368:744-53.

Raby BA, Hwang E-S, Van Steen K, et al. 2006. T-bet polymorphisms are associated with asthma and airway hyperresponsiveness. Am J Respir Crit Care Med, 173:64-70.

Rouhani FN, Meitin CA, Kaler M, et al. 2005. Effect of tumor necrosis factor antagonism on allergen-mediated asthmatic airway inflammation. Respir Med, 99:1175-82.

Saeki S, Matsuse H, Kondo Y, et al. 2004. Effects of antiasthmatic agents on the functions of peripheral blood monocyte-derived dendritic cells from atopic patients. J Allergy Clin Immunol, 114:538-44.

Schering-Plough announces global agreement with Novartis to develop once-daily combination therapy for asthma and COPD [news release] Schering-Plough Corporation; August 14, 2006. Accessed 29 June 2007. URL: http://www.schering-plough.com/schering_plough/news/release. jsp?releaseID $=895303$.

Sears M, Ottosson A, Radner F, et al. 2007. Safety of formoterol in asthma trials [abstract]. Presented at the European Respiratory Society Annual Congress, September 15-19, 2007, Stockholm, Sweden. Abstract number 1586.

Selroos O. 2007. Some aspects on comparative efficacy studies with inhaled corticosteroids in asthma. Curr Drug Ther, 2:57-54.

Sin DD, Man J, Sharpe H, et al. 2004. Pharmacological management to reduce exacerbations in adults with asthma. A systematic review and meta-analysis. JAMA, 292:367-76.

Silkoff PE, Carlson M, Bourke T, et al. 2004. The Aerocrine exhaled nitric oxide monitoring system NIOX is cleared by the US Food and Drug Administration for monitoring therapy in asthma. $J$ Allergy Clin Immunol, 114:1241-56.
Solèr M, Matz J, Townley R, et al. 2001. The anti-IgE antibody omalizumab reduces exacerbations and steroid requirement in allergic asthmatics. Eur Respir J, 18:254-61.

Sopo SM, Macchiaiolo M, Zorzi G, et al. 2004. Sublingual immunotherapy in asthma and rhinoconjunctivitis; systematic review of paediatric literature. Arch Dis Child, 89:620-24.

Strunk RC, Bloomberg GR. 2006. Omalizumab for asthma. N Engl J Med, 354:2689-95.

Szefler SJ, Phillips BR, Martinez FD, et al; for the Childhood Asthma Research and Education Network of the National Heart, Lung, and Blood Institute. 2005. Characterization of within-subject responses to fluticasone and montelukast in childhood asthma. J Allergy Clin Immunol, 115:233-42.

Tantisira KG, Hwang ES, Raby BA, et al. 2004. TBX21: A functional variant predicts improvement in asthma with the use of inhaled corticosteroids. PNAS, 101:18099-104.

Tattersfield AE, Löfdahl C-G, Postma DS, et al. 2001. Comparison of formoterol and terbutaline for as-needed treatment of asthma: a randomised trial. Lancet, 357:257-61.

Taylor DR, Drazen JM, Herbison GP, et al. 2000. Asthma exacerbations during long term $\beta$ agonist use: influence of $\beta_{2}$ adrenoceptor polymorphism. Thorax, 55:762-7.

van der Woude HJ, Boorsma M, Bergqvist PBF, et al. 2004. Budesonide/ formoterol in a single inhaler rapidly relieves methacholine-induced moderate-to-severe bronchoconstriction. Pulm Pharmacol Ther, 17:89-95.

Vogelmeier C, D'Urzo A, Pauwels R, et al. 2005. Budesonide/formoterol maintenance and reliever therapy: an effective asthma treatment option? Eur Respir J, 26:819-28.

Walders N, Kopel SJ, Koinis-Mitchell D, et al. 2005. Patterns of quickrelief and long-term controller medication use in pediatric asthma. J Pediatr, 146:177-82.

Wang LC, Lee JH, Yang YH, et al. 2007. New biological approaches in asthma: DNA-based therapy. Curr Med Chem, 14:1607-18.

Wechsler ME. 2006. Managing asthma in the 21st century: role of pharmacogenetics. Pediatr Ann, 35:660-662, 664-9.

Wechsler ME, Lehman E, Lazarus SC, et al; for the National Heart, Lung, and Blood Institute's Asthma Clinical Research Network. 2006 $\beta$-adrenergic receptor polymorphisms and response to salmeterol. Am J Respir Crit Care Med, 173:519-26.

Wechsler ME, Israel E. 2005. How pharmacogenomics will play a role in the management of asthma. Am J Respir Crit Care Med, 172:12-8.

Wenzel SE. 1998. Antileukotriene drugs in the management of asthma. JAMA, 280:2068-9.

Williams LK, Pladevall M, Hugo X, et al. 2004. Relationship between adherence to inhaled corticosteroids and poor outcomes among adults with asthma. J Allergy Clin Immunol, 114:1288-93. 
